\title{
A Decision Support System Based on Degree-Days to Initiate Fungicide Spray Programs for Peach Powdery Mildew in Catalonia, Spain
}

\author{
Neus Marimon, ${ }^{1,2}$ Iban Eduardo, ${ }^{2}$ Joaquín Martínez-Minaya, ${ }^{3}$ Antonio Vicent, ${ }^{4}$ and Jordi Luque ${ }^{1, \dagger}$ \\ ${ }^{1}$ Plant Pathology, Institut de Recerca i Tecnologia Agroalimentàries (IRTA), Carretera de Cabrils km 2, 08348 Cabrils, Spain \\ ${ }^{2}$ Centre de Recerca en Agrigenòmica (CRAG), CSIC-IRTA-UAB-UB, UAB Campus, 08193 Bellaterra, Spain \\ ${ }^{3}$ Basque Center for Applied Mathematics (BCAM), Mazarredo 14, 48009 Bilbao, Spain \\ ${ }^{4}$ Centre de Producció Vegetal i Biotecnologia, Institut Valencià d'Investigacions Agràries (IVIA), 46113 Moncada, Spain
}

\begin{abstract}
The incidence of peach powdery mildew (PPM) on fruit was monitored in commercial peach orchards to i) describe the disease progress in relation to several environmental parameters and ii) establish an operating threshold to initiate a fungicide spray program based on accumulated degree-day (ADD) data. A beta-regression model for disease incidence showed a substantial contribution of the random effects orchard and year, whereas relevant fixed effects corresponded to ADD, wetness duration, and ADD considering vapor pressure deficit and rain. When beta-regression models

was established at $220 \mathrm{ADD}$, coinciding with a PPM incidence in fruit around 0.05 . A validation was further conducted by comparing PPM incidence in i) a standard, calendar-based program, ii) a program with applications initiated at $220 \mathrm{ADD}$, and iii) a nontreated control. A statistically relevant reduction in disease incidence in fruit was obtained with both fungicide programs, from 0.244 recorded in the control to 0.073 with the 220 ADD alert program, and 0.049 with the standard program. The 220-ADD alert program resulted in $33 \%$ reduction in fungicide applications.
\end{abstract} were fitted for each orchard and year considering only ADD, disease onset was observed at $242 \pm 13 \mathrm{ADD}$ and symptoms did not develop further after $484 \pm 42$ ADD. An operating threshold to initiate fungicide applications
Keywords: disease control, epidemiology, beta regression, Podosphaera pannosa, Prunus persica
The fungus Podosphaera pannosa (Wallr.) de Bary is one of the causal agents of the powdery mildew that occurs on peach, nectarines, and flat fruit (Farr and Rossman 2019). Other powdery mildew species can be found on this fruit tree species, such as $P$. clandestina, P. leucotricha, and P. tridactyla (Farr and Rossman 2019), but $P$. pannosa is widely recognized as the main causal agent of the peach powdery mildew (PPM). The species $P$. pannosa is a cosmopolitan biotrophic pathogen that has been reported from over 40 peach-growing countries in the world (Amano 1986; Farr and Rossman 2019). It is also known to affect other Rosaceae species, mainly included in the genera Prunus and Rosa (Farr and Rossman 2019). On peach, the fungus infects fruit, leaves, buds, shoots, and twigs (Grove 1995; Ogawa and English 1991), showing a distinguishable white-grayish mycelium developing on the surface of the affected parts. The pathogen overwinters as dormant mycelium in latent buds (Ogawa and English 1991; Weinhold 1961; Yarwood 1957), and in chasmothecia produced in the epiphytic mycelium of infected twigs and leaves (Butt 1978). Primary infections on the tree green parts

${ }^{\dagger}$ Corresponding author: J. Luque; jordi.luque@irta.cat

Funding: Research funded by the Instituto Nacional de Investigación y Tecnología Agraria y Alimentaria (INIA), Spain, grant RTA2013-00004C03-01, and with matching funds from the European Regional Development Fund (ERDF). Neus Marimon was supported by INIA with a predoctoral grant (CPD2015-0142). Jordi Luque and Iban Eduardo were partially supported by CERCA program, Generalitat de Catalunya (Spain). Joaquín Martínez-Minaya would like to thank for the support by the Basque Government through the BERC 2018-2021 program and by the Ministry of Science, Innovation and Universities: BCAM Severo Ochoa accreditation SEV-20170718 .

*The $\boldsymbol{e}$-Xtra logo stands for "electronic extra" and indicates that three supplementary figures and one supplementary table are published online.

The author(s) declare no conflict of interest.

Accepted for publication 16 March 2020.

(C) 2020 The American Phytopathological Society occur in spring, when primary inoculum (ascospores) is available and favorable conditions are met. Infections from latent mycelium that overwintered in buds have also been reported (Weinhold 1961). Conidia released from these primary colonies disperse in air and initiate secondary infections throughout the season (Grove 1995; Jarvis et al. 2002). Infection of fruit, if severe, makes the fruit commercially unacceptable (Weinhold 1961), thus causing important economic losses.

Data on potential yield reduction by PPM have been previously reported in some countries. In California, Ogawa and Charles (1956) reported that the amount of marketable peaches from fungicidesprayed trees was about $20 \%$ greater than those from unsprayed trees. Grove (1995) reported that crop losses resulting from fruit infections may reach $50 \%$ on Japanese plums, apricots, nectarines, and peaches. Unfortunately, no data on potential production losses are available in Spain, where this study has been carried out. Spain ranks as the second country in the world, after China, in terms of cultivated area (86,000 ha) and annual fruit production of peaches (1.5 million tons in 2016), followed by Italy, the U.S.A., and Greece (FAO 2019; MAPA 2019). These figures account for about $6 \%$ of the total world crop area and 7\% of world production. In Spain, PPM is endemic but quantitative data on potential production losses are not available.

The control of PPM is usually achieved through the applications of fungicides (Grove 1995; Hollomon and Wheeler 2002; Ogawa and English 1991). The most used fungicides are sterol biosynthesis inhibitors (SBI), quinone outside inhibitors (QoI), protein synthesis inhibitors, and various inorganic multisite activity products including sulfur derivatives. Foliar fungicides, starting at petal fall or the beginning of fruit set, are sprayed routinely to protect peach fruit from infection (Grove 1995; Reuveni 2001), as fruit are susceptible from the early stages of fruit growth to the beginning of pit hardening (Ogawa and English 1991). In Spain, four to seven fungicide applications in a season are generally needed, which is comparable to other Mediterranean countries where peaches are grown (Reuveni 2001). In California, it has been reported that three applications are enough to control the disease (Ogawa and Charles 1956; Ogawa and English 1991). However, fungicide applications are made on a calendar basis (Ogawa and English 1991) since, to our knowledge, no 
epidemiological models to predict the risk infection of PPM are currently available.

Disease prediction is required to apply plant protection products in rational, sustainable integrated strategies, which are intended to keep control effectiveness against plant diseases while reducing the application costs and the potential risks to the environment and public health (Jørgensen et al. 2017). Thus, optimizing timing of fungicide application is fully desirable for economic and environmental reasons. Several epidemiological models have been developed for powdery mildews in different crops, including apple, barley, grape, rose, rubber, sugar beet, and tomato, as reviewed by Jarvis et al. (2002), cherry (Grove et al. 2000), cucurbits (Sapak et al. 2017), mango (Nasir et al. 2014), and wheat (Cao et al. 2015). In general terms, models focus on the prediction of i) the critical date for a single fungicide application, ii) the date to initiate the fungicide program, or iii) the timing of fungicide applications in intensive spray programs, as reviewed by Butt (1978).

Empirical (i.e., correlative) and mechanistic (i.e., process-based) modeling approaches have been used to develop decision support systems (DSSs) for plant disease management. Empirical models are correlative in nature, so their predictive ability is limited by the scope of the data (Madden and Ellis 1988). Mechanistic models are developed from controlled experiments to quantify the effects of environmental factors on the different components of the disease cycle (De Wolf and Isard 2007). Mechanistic models are generally considered more robust for extrapolation, but epidemics are sometimes more complex than a simple combination of their monocyclic components.

We aimed at acquiring new knowledge on the disease onset and progress of PPM under the crop conditions in Catalonia, Northeast Spain, and to develop and validate a DSS adapted to this area. In a field survey conducted in $2015, P$. pannosa was the only powdery mildew species detected on peach in the study area. The specific objectives of this study were therefore i) to describe the disease onset and progression of PPM caused by $P$. pannosa on peach and nectarine fruit in terms of incidence along the season, ii) to develop a simple epidemiological model to estimate the disease incidence in relation to temperature, and iii) to evaluate the performance of this empirical model as a DSS to initiate the fungicide spray program for PPM management.

\section{Materials and Methods}

Experimental sites. The incidence of powdery mildew on peach and nectarine fruit was monitored yearly along the growth season in the period 2013 to 2015 in eight commercial orchards (1 to 8) located in Lleida, Catalonia, Spain, and aged 4 to 8 years at the beginning of the experiment (Table 1). Most orchards were nectarine crops whereas only one was cultivated for peach, and an additional one for platerine. The commercial validation of the DSS, as described by
Magarey and Sutton (2007), for the onset of fungicide applications was conducted in 2017 in six orchards, namely 2, 8, and four additional ones, 9 to 12 (Table 1). All orchards (1 to 12) were located within a radius of approximately $10 \mathrm{~km}$. All varieties in the orchards were grafted onto 'GF-677' rootstock except for orchard 10, where they were grafted onto 'Garnem.' Trees in the orchards were arranged around 4 to $5 \times 2$ to $3 \mathrm{~m}$, trained in four scaffolds open vase, and drip-irrigated, which is locally common in the area. The climate in the area is BSk (tropical and subtropical steppe climate), according to Köppen-Geiger's climate classification system (Kottek et al. 2006).

Dynamics of powdery mildew symptoms on fruit. For each growing season and experimental plot, symptoms of PPM were recorded on fruit starting from the $50 \%$ blossom biofix $(\mathrm{BBCH}$ scale 65, see Meier (2001)) occurring in mid-March, until no further disease progression was noticed for up to 2 to 3 weeks (BBCH scale 77 to 79), which occurred in mid-June to early July depending on the year. Observations of PPM symptoms were carried out on a weekly basis but twice a week in some sites and seasons, especially when incidence progressed rapidly. The observations were conducted on five contiguous trees, which were not treated with fungicides during the growing season, thus allowing for a natural progress of disease. Monitored trees were surrounded by 1 to 2 rows of nontreated trees to avoid spray drift, as confirmed in earlier observations. In each tree, 3 to 4 scaffolds were selected and the central third of each branch was marked to set homogeneous sampling conditions within trees and among experimental sites. All the fruit in the selected branch sections were recorded as either symptomatic or not and those showing symptoms were individually labeled. At the end of the monitoring period, all fruit in each monitored branch sections were counted, and disease incidence was calculated as the proportion of symptomatic fruit ( 0 to 1$)$ for each monitoring period, branch, tree, and experimental site combination. Any diseased fallen fruit during the monitoring period was considered as a diseased fruit to avoid underestimates of disease incidence (i.e., decrease) with time.

Environmental data. A wireless cellular data logger (model Em50G, from Decagon Services, Pullman, WA, U.S.A.) was located in each experimental site, less than $50 \mathrm{~m}$ from the marked trees. The data logger was used to measure the air temperature, relative humidity, rainfall, and wetness duration at 1-h intervals during the whole experimental period. Environmental variables were summarized for each period between two consecutive symptom evaluations as follows: mean values of temperature and relative humidity, and accumulated values of rainfall and leaf wetness duration, the latter either expressed as total number of minutes or time proportion within the whole interval. In addition, degree-days (DD) were calculated according to Zalom et al. (1983), by using the single-sine method and setting $10^{\circ} \mathrm{C}$ and $35^{\circ} \mathrm{C}$ as the lower and upper thresholds,

Table 1. Characteristics of the commercial orchards used in this study and years corresponding to symptom monitoring, model fitting (train dataset), model evaluation (test dataset), and commercial validation

\begin{tabular}{|c|c|c|c|c|c|c|c|c|}
\hline \multirow[b]{2}{*}{ Orchard no. } & \multicolumn{2}{|c|}{$\begin{array}{c}\text { UTM coordinates } \\
\text { (WGS 84, } 31 \text { T) }\end{array}$} & \multirow[b]{2}{*}{ Crop } & \multirow[b]{2}{*}{ Cultivar } & \multirow{2}{*}{$\begin{array}{c}\text { Symptom } \\
\text { monitoring (year) }\end{array}$} & \multirow[b]{2}{*}{ Train dataset (year) } & \multirow[b]{2}{*}{ Test dataset (year) } & \multirow{2}{*}{$\begin{array}{c}\text { Commercial } \\
\text { validation (year) }\end{array}$} \\
\hline & $X$ & $Y$ & & & & & & \\
\hline 1 & 287680 & 4602661 & Nectarine & Red Jim & $2013-15$ & 2013-15 & - & - \\
\hline 2 & 297674 & 4602928 & Nectarine & Red Jim & $2013-15$ & 2014 & 2013 & 2017 \\
\hline 3 & 289237 & 4613448 & Peach & Albesa Red & 2013-14 & 2013 & - & - \\
\hline 4 & 288554 & 4613923 & Platerine & ASF 07.78 & 2015 & - & - & - \\
\hline 5 & 283489 & 4619988 & Nectarine & Venus & 2013 & - & 2013 & - \\
\hline 6 & 302991 & 4627916 & Nectarine & Nectareine & $2014-15$ & 2014 & 2015 & - \\
\hline 7 & 287918 & 4597751 & Nectarine & Venus & 2013-14 & $2013-14$ & - & - \\
\hline 8 & 287141 & 4609517 & Nectarine & Autumn free & $2013-15$ & $2013-15$ & - & 2017 \\
\hline 9 & 287972 & 4603490 & Nectarine & Tarderina & - & - & - & 2017 \\
\hline 10 & 286696 & 4605773 & Nectarine & Independence & - & - & - & 2017 \\
\hline 11 & 289380 & 4612041 & Nectarine & Extreme Red & - & - & - & 2017 \\
\hline 12 & 282806 & 4614805 & Nectarine & Nectatinto & - & - & - & 2017 \\
\hline
\end{tabular}


respectively. Thresholds were determined from the values reported for P. fuliginea (Jarvis et al. 2002). Accumulated degree-days (ADD) for each monitoring date were calculated starting from the $50 \%$ blooming biofix date. Finally, combined environmental variables were included in the analyses (Table 2).

Disease progress modeling. Beta regression is commonly used for variables that assume values in the unit interval $(0,1)$. This method overcomes the drawbacks of the traditional data transformations, so it allows a direct interpretation of model parameters in terms of the original data. The analysis is not sensitive to the sample size, and posterior distributions are expected to concentrate well within the bounded range of proportions (Ferrari and Cribari-Neto 2004; Martínez-Minaya et al. 2019). As in generalized linear models, the mean $\left(\mu_{i}\right)$ is linked to the linear predictor using the logit link function:

$$
\operatorname{logit}\left(\mu_{i}\right)=\beta_{0}+\sum_{j=1}^{N_{\beta}} \beta_{j} x_{j i}+\sum_{k=1}^{N_{v}} v_{k i} \quad i=1, \ldots, n
$$

where $\beta_{0}$ is the intercept of the model, $\beta_{j}$ are the parameters corresponding to the fixed effects of the model, and $v_{k i}$ represent $k$ unstructured error terms (random effects).

Commercial validation of the DSS to initiate fungicide applications. From the field observations, early primary PPM symptoms were observed at approximately 240 ADD on average (242.0 \pm 13.1 ADD). Moreover, an average incidence of 0.05 was estimated at $239.1 \pm$

Table 2. Name and description of the environmental variables used for model fitting

\begin{tabular}{ll}
\hline Variable & \multicolumn{1}{c}{ Description } \\
\hline Tm & Mean temperature $\left({ }^{\circ} \mathrm{C}\right)$ \\
Rain & Rainfall (mm) \\
RH & Relative humidity (\%) \\
VPD & Vapor pressure deficit, as described by \\
& Martínez-Minaya et al. (2019). Used to \\
& calculate ADDvpd \\
WetnessD & Leaf wetness duration (minutes) \\
WetnessP & Leaf wetness duration expressed as \\
& percentage of time \\
ADD & ADD calculated by the simple sinus method \\
& (Zalom et al. 1983) \\
ADD2 & ADD calculated as described by Martínez- \\
& Minaya et al. $(2019)$ \\
ADDrh70-90 & ADD of days with 70 $<$ RH $<90 \%$ \\
ADDno_rain & ADD of days with Rain $<2$ mm \\
ADDno_wet & ADD of days with $70<$ RH $<90 \%$ and Rain \\
& $<2$ mm, based on Toma and Ivascu $(1998)$ \\
ADDno_wet2 & ADD of days with WetnessP $<70 \%$, based on \\
& Grove $(1995)$ \\
ADDvpd & ADD2 of days with VPD $<4$ (Martínez- \\
& Minaya et al. 2019) \\
ADDwet & ADD2 of days with VPD $<4$ and Rain $>2$ mm \\
& (modified from Martínez-Minaya et al. \\
ADDwet2 & 2019) \\
& ADD of days with VPD $<4$ and Rain $>2$ mm \\
\hline
\end{tabular}

18.1 ADD with the beta regression model described here. Thus, an operating alert threshold to initiate fungicide applications was chosen at $220 \mathrm{ADD}$. This value was chosen considering logistic constraints at the farm level to provide growers with a reasonable period to initiate fungicide sprays. Roughly, this 20 ADD difference was equivalent to approximately 2 days, as DD values observed in this period were about $10 \mathrm{DD}$ a day.

According to Magarey and Sutton (2007), commercial evaluation considers if the model can predict the appropriate deployment of disease management measures. Commercial validation is usually performed by comparing disease incidence and/or severity of a model-driven fungicide spray schedule with that of a routine calendar program. Six orchards, namely 2 , and 8 to 12 (Table 3), were used in this study. In each orchard, three fungicide programs were evaluated. First was the standard, calendarbased fungicide program, which was applied under farmers' criteria and coinciding with the European Directive on Sustainable Use of Pesticides (2009/128/EC). This program was applied in all orchards after petal fall, well before the 220-ADD alert. Second was the fungicide program starting at the 220-ADD alert, which was further continued on a calendar basis, and with same applications and dates as the standard. The third was the control, nontreated group of trees. Each experimental unit consisted of five contiguous trees that were surrounded by 1 to 2 rows of untreated trees to avoid spray drift. The selection of fungicides to be used in each application time, as well as the application calendars, were left to each farmer's criteria, but were the same in the calendar-based program and after the 220-ADD alert spray program conducted in each orchard. Fungicides used in the orchards during the commercial validation were included in the chemical groups of triazoles, dithiocarbamates, benzamides, strobilurins, pyrimidines, quinolines, and inorganic fungicides.

The ADD values were calculated daily as described above for all experimental orchards starting at $50 \%$ blooming date, the latter being in the range 7 to 9 March 2017. When the 220-ADD alert was approaching (i.e., around 200 ADD; from 18 to 24 April 2017), PPM incidence was evaluated in all combinations of fungicide programs and orchards. At the end of the experimental period, when no further disease progression was observed (values from 570 ADD to 760 ADD; from 8 to 12 June 2017), disease incidence was again assessed in all experimental sites and trees.

Statistical analyses. The beta regression to model PPM disease dynamics was fitted following a Bayesian hierarchical approach with integrated nested Laplace approximations (INLA) (Rue et al. 2009). This methodology uses Laplace approximations (Tierney and Kadane 1986) to get the posterior distributions in latent Gaussian models (LGMs) (Rue et al. 2009). Vague Gaussian distributions were used here for the parameters involved in the fixed effects $\beta_{j} \sim$ $N\left(0,10^{-5}\right)$. Precision of the beta distribution $(\phi)$ was reparametrized as $\phi=\exp (\alpha)$ to ensure that $\phi$ was a positive parameter. We assumed pc-priors on the log-precision for both parameters. The computational implementation R-INLA (Rue et al. 2009) for R (R Core Team 2018) was used to perform approximate Bayesian inference. In order to conduct the analysis in our data, values of the response variable were transformed to be included in the interval $(0,1)$ dividing by the maximum PPM incidence recorded in each orchard and year

Table 3. Most relevant dates and accumulated degree days (ADD) values recorded during the commercial validation of the 220-ADD alert spray program for the control of peach powdery mildew in 2017 in six nectarine orchards

\begin{tabular}{|c|c|c|c|c|c|c|c|c|c|}
\hline \multirow[b]{2}{*}{ Orchard no. } & \multirow[b]{2}{*}{$50 \%$ bloom date } & \multirow[b]{2}{*}{ Petal fall } & \multicolumn{3}{|c|}{ 220-ADD alert pre-evaluation } & \multicolumn{2}{|c|}{$\begin{array}{c}\text { Application at 220- } \\
\text { ADD alert }\end{array}$} & \multicolumn{2}{|c|}{ Final evaluation } \\
\hline & & & Date & ADD & Incidence & Date & ADD & Date & ADD \\
\hline 2 & $8 \mathrm{Mar}$ & $15 \mathrm{Mar}$ & $21 \mathrm{Apr}$ & 214.9 & 0.000 & $22 \mathrm{Apr}$ & 219.4 & 9 Jun & 654.2 \\
\hline 8 & 7 Mar & 13 Mar & $18 \mathrm{Apr}$ & 207.9 & 0.001 & $21 \mathrm{Apr}$ & 222.7 & 9 Jun & 636.3 \\
\hline 9 & 7 Mar & 15 Mar & $19 \mathrm{Apr}$ & 228.6 & 0.000 & $20 \mathrm{Apr}$ & 232.8 & 8 Jun & 675.2 \\
\hline 10 & 7 Mar & $29 \mathrm{Mar}$ & $21 \mathrm{Apr}$ & 213.5 & 0.006 & $22 \mathrm{Apr}$ & 219.4 & 12 Jun & 648.4 \\
\hline 11 & 9 Mar & $21 \mathrm{Mar}$ & $21 \mathrm{Apr}$ & 222.7 & 0.009 & $20 \mathrm{Apr}$ & 216.9 & 12 Jun & 758.9 \\
\hline 12 & 8 Mar & $30 \mathrm{Mar}$ & $24 \mathrm{Apr}$ & 208.1 & 0.000 & $27 \mathrm{Apr}$ & 217.8 & 8 Jun & 572.8 \\
\hline
\end{tabular}


combination. As a common practice in beta regression, $0 \mathrm{~s}$ and $1 \mathrm{~s}$ were settled to 0.01 and 0.99 , respectively.

A joint analysis including all orchards and years was conducted. The dataset including all orchards and years $(n=14)$ was split into a train dataset $(n=11)$ and a test dataset $(n=3)$ (Table 1). Pearson correlations among covariates were calculated (Supplementary Fig. $\mathrm{S} 1$ ), and those greater than 0.7 were not further considered to minimize potential multicollinearity issues (Dormann et al. 2013). Thus, variables for final analyses were restricted to seven, namely ADD, ADDvpd, ADDwet, Rain, RH, Tm, and WetnessP (Table 2). Two additional random independent effects, year and orchard, were included. All possible models $(n=512)$ were fitted to the train dataset and the best models were selected based on the Watanabe Akaike Information Criterion (WAIC) (Watanabe 2010), which is the sum of two components, one quantifying for the model fit and the other one evaluating model complexity. Models with the lowest WAIC values were selected. The importance of the covariates in the models was checked based on the values of their coefficients. Median values of the posterior predictive distribution were linearly regressed against the observed values and $\mathrm{R}^{2}$ of models were computed. The mean absolute error (MAE), mean square error (MSE), and root mean square error (RMSE) were also calculated. The best model was then evaluated using the test dataset. Linear regression of predicted versus observed values including $\mathrm{R}^{2}$, MAE, MSE, and RMSE values were also calculated. Finally, data from each separate orchardyear combination were analyzed similarly but including only ADD as a covariate.

In the commercial validation experiment, disease incidence data at the end of the experimental period were analyzed with a logistic regression and binomial distribution. Fungicide programs (i.e., calendar-based, 220-ADD alert, and nontreated control) were considered as a fixed factor and orchards as a random blocking factor. The nontreated control was used as the reference level and the odds ratios for the calendar-based and 220-ADD alert spray programs were calculated including their corresponding $95 \%$ credibility intervals. R-INLA for $\mathrm{R}$ was used to perform approximate Bayesian inference with the prior distributions provided by default.

\section{Results}

Dynamics of powdery mildew symptoms on fruit. Only datasets with final PPM incidence on fruit equal or higher than 0.05 in the orchards were used in this study, i.e., a total of 14 datasets resulting from the combination of the experimental orchards and monitored years (Fig. 1). Final incidence values ranged among orchards and years between 0.05 and 0.96 . Four orchard-year combinations were in the range 0.05 to 0.20 final PPM incidence, eight in the range 0.20 to 0.60 , and two over 0.80 (Fig. 1). Moreover, first symptoms were noticed at variable dates and their equivalent ADD values among orchards and years. Field observations revealed that first PPM occurrences on fruit were noticed on average at 240 ADD after the $50 \%$ blooming biofix (mean \pm std. err.: $242.0 \pm 13.1$ ADD; median: 241; range: 144 to 311 ). At this stage, first infection signs were noticed at 0.045 incidence on average (range: 0.010 to 0.115 ). On a calendar basis, most of these primary infection symptoms were noticed between the last week of April and the two first weeks of May (range: 18 Apr to 14 May). PPM incidence increased in the experimental orchards roughly until June, and last new symptoms were mostly detected at 460 to 480 ADD (median: 460 ADD; mean $484 \pm 42.2$; range 283 to 833 ). Last new symptoms on fruit were early detected in May (first to third week) in some orchard-year combinations, whereas in other cases they were detected as late as in July (first week).

The best models for PPM incidence fitted to the train dataset are shown in Table 4. Models not including the random effects year $(v)$ and orchard $(w)$ were ranked very low based on their WAIC values. Four out of the five best models included the fixed effects ADD, ADDvpd, ADDwet, and WetnessP. The finally selected model, with the lowest WAIC value, included those fixed effects and the random effects year and orchard. Linear regression of the median posterior predictive distribution against observed values accounted for more than $84 \%$ of the total variance $\left(R^{2}=0.842\right)$ (Supplementary Fig. $\mathrm{S} 2 \mathrm{~A})$. The MAE for this model was 0.090, the MSE was 0.014, and the RMSE was 0.119. In the selected model, ADD, ADDvpd, ADDwet, and WetnessP were relevant. The parameter for the fixed effect ADD had a mean posterior distribution of 0.668 with a $95 \%$ credible interval $[0.442,0.902]$ (Table 5). The parameter for the fixed effect ADDvpd had a mean posterior distribution of -2.294 with a $95 \%$ credible interval $[-3.187,-1.459]$. The parameter for the fixed effect ADDwet had a mean posterior distribution of 4.881 with a $95 \%$ credible interval $[3.035,6.824]$. The parameter for the fixed effect WetnessP had a mean posterior distribution of -1.891 with a $95 \%$ credible interval $[-3.063,-0.711]$. None of the credible intervals overlapped with zero. Posterior distribution of the hyperparameters are displayed in Table 5, showing that random effects explain some of the variability of the response variable, and it is important to consider them in the model. The fixed effects ADD and ADDwet had positive effects on the expected incidence of PPM whereas ADDvpd and WetnessP had negative effects. When the selected model was applied to the test dataset, MAE ranged from 0.035 to 0.235 , MSE from 0.002 to 0.082 , RMSE from 0.040 to 0.286 among datasets. When the median of the posterior predictive distribution was linearly regressed against the observed data, values of $\mathrm{R}^{2}$ ranged from 0.215 in orchard 6 in 2015 to 0.236 in orchard 2 in 2013. In general, residuals showed a poor graphical fit (Supplementary Fig. S2B, C, D).

The beta regression models for each orchard-year combination that included only ADD as an explanatory variable were able to accommodate dynamics of PPM incidence at a different degree, despite the large differences observed in disease progress and final incidences (Fig. 1). The mean of the posterior distribution for the intercept $\left(\beta_{0}\right)$ ranged from -12.2 in orchard 3 to -4.9 in orchard 2 in 2013 , from -16.8 in orchard 1 to -5.2 in orchard 7 in 2014, and from -11.7 in orchard 8 to -4.6 in orchard 6 in 2015 (Table 6 ). The mean of the posterior distribution for the parameter of $\operatorname{ADD}\left(\beta_{1}\right)$ ranged from 1.6 in orchard 2 to 6.1 in orchard 3 in 2013, from 1.7 in orchard 7 to 5.9 in orchard 1 in 2014, and from 1.3 in orchard 6 to 3.8 in orchard 8 in 2015 (Table 6). Based on the beta regression models, between 107.2 ADD (orchard 2, 2013) and 278.1 ADD (orchard 1, 2013) were needed to reach PPM incidences of 0.01 in the 2013-15 monitoring period (Table 7). In addition, between 161.6 ADD (orchard 7, 2014) and 389.9 ADD (orchard 1, 2013) were needed to reach 0.10 PPM incidence in the same period. Highest annual mean values for ADD estimations at 0.01 to 0.10 incidence were obtained in 2015, whereas lowest estimates were obtained in 2014. On average, 187.1 to 264.0 ADD were needed to reach PPM incidences between 0.01 and 0.1 , respectively, among orchards and years (Table 7). An average of 239.1 ADD for 0.05 PPM incidence was determined for all orchard and year combinations, which was comparable with the first PPM occurrences visually noticed in the orchards.

Commercial validation of the DSS to initiate fungicide applications. Two of the six orchards evaluated in 2017, namely orchards 9 and 12, were excluded from the commercial validation as PPM symptoms recorded at the end of the experimental period were $<1 \%$ and we thought that data from those orchards might not be adequate for the statistical analyses. Thus, only data from four orchards $(2,8$, 10, and 11) were used in the analyses (Supplementary Fig. S3). Disease incidence values recorded in the nontreated control ranged from 0.157 (orchard 8) to 0.411 (orchard 2). Mean PPM incidence recorded in the nontreated control was $0.244 \pm 0.114$ (std. dev.) (Fig. 2), with a total sample size of 5,894 fruit. Mean PPM incidence recorded in the calendar-based spray program was $0.049 \pm 0.032$, with a total sample size of 5,465 fruit. Mean PPM incidence recorded in the $220-A D D$ alert spray program was $0.073 \pm 0.044$, with a total sample size of 5,883 fruit.

The odds ratio was 0.199 (credibility interval: 0.175 to 0.225 ) for the calendar-based spray program and $0.116(0.099$ to 0.135$)$ for the $220-A D D$ alert spray program. The $95 \%$ credibility interval of the odds ratio was lower than 1 , so both spray programs reduced PPM incidence compared with the reference level (nontreated control). The odds of PPM incidence in the calendar-based spray program 
were 8.63 times less than in the nontreated control, whereas the odds corresponding to the 220-ADD alert spray program were 5.02 times less than in the control. The $95 \%$ credibility intervals of the odds ratio for the calendar-based and the 220-ADD alert spray programs did not overlap, being lower for the calendar-based treatment. Therefore, higher reduction of PPM incidence compared with the nontreated control was obtained with the calendar-based spray program than with the 220-ADD alert spray program.
Regarding the total number of fungicide applications in the calendar-based program, it ranged from 4 (orchard 2 and 10) to 7 (orchard 8). Meanwhile, the number of fungicide applications in the 220-ADD alert spray program ranged from 2 (orchard 10) to 5 (orchard 8). This represents, in percentage, and compared with the calendar-based program, a reduction in the numbers of fungicide applications from $25 \%$ (orchard 2) to $50 \%$ (orchard 10) (mean: $33.3 \%$ ) (Supplementary Table S1).
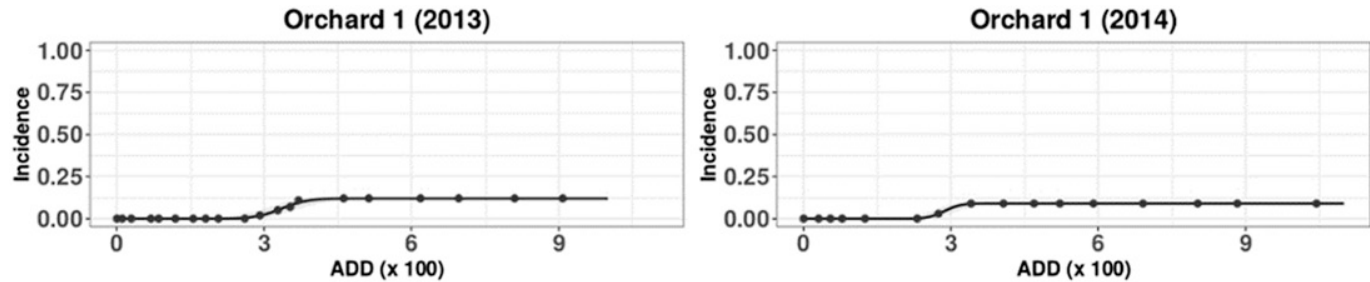

Orchard 1 (2015)
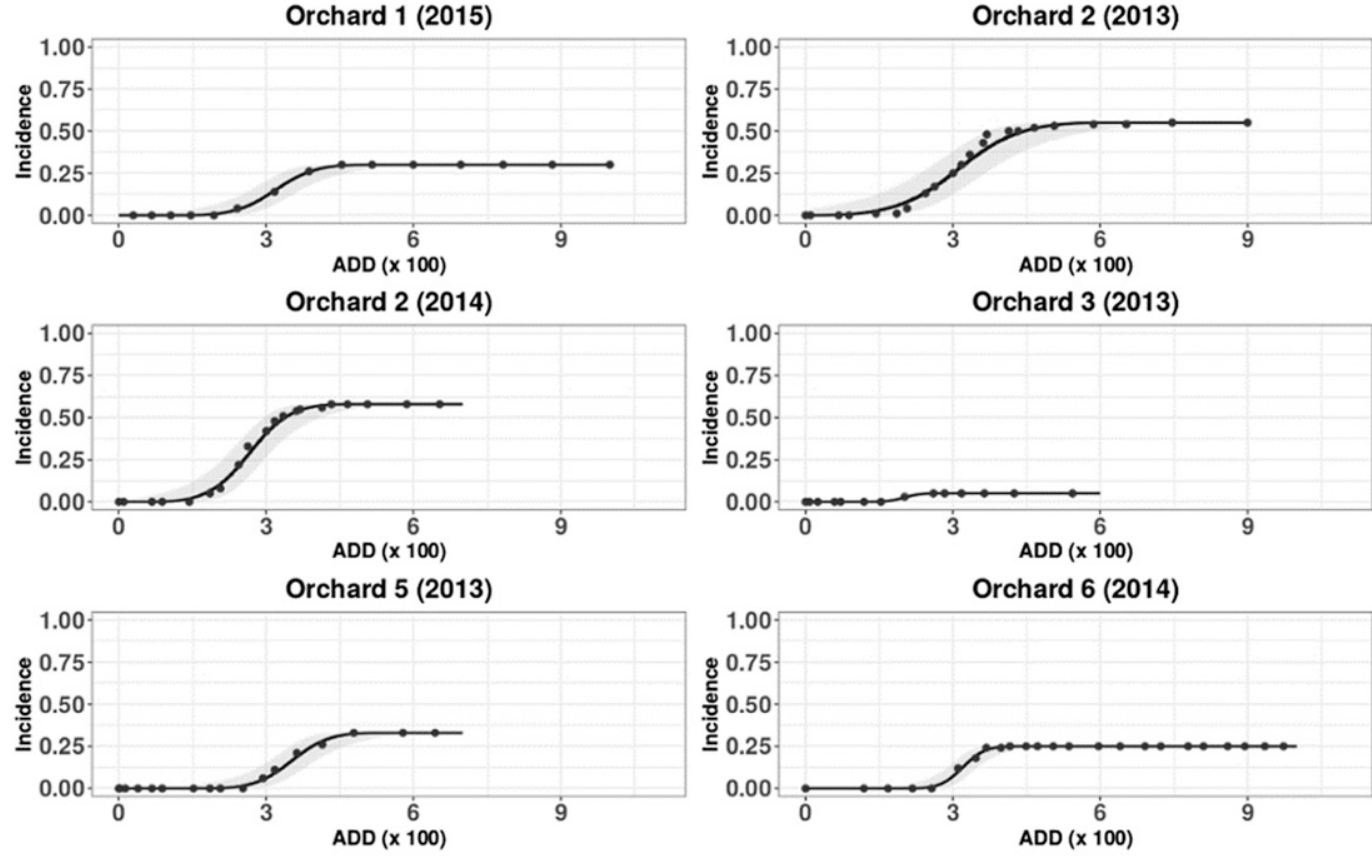

Orchard 6 (2015)
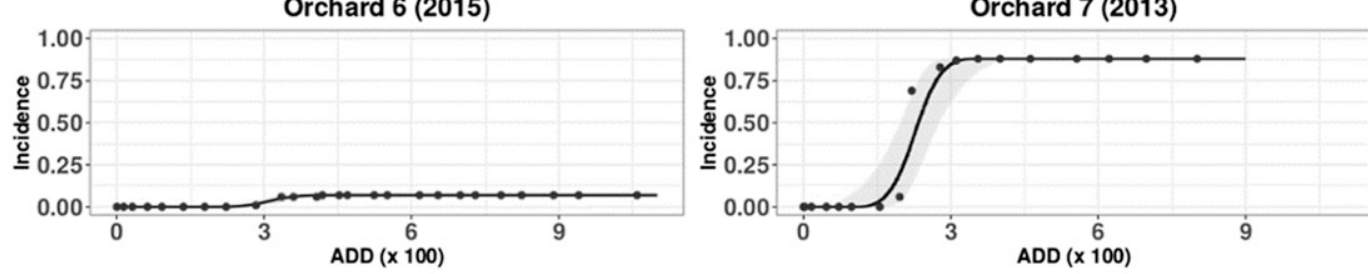

Orchard 7 (2014)
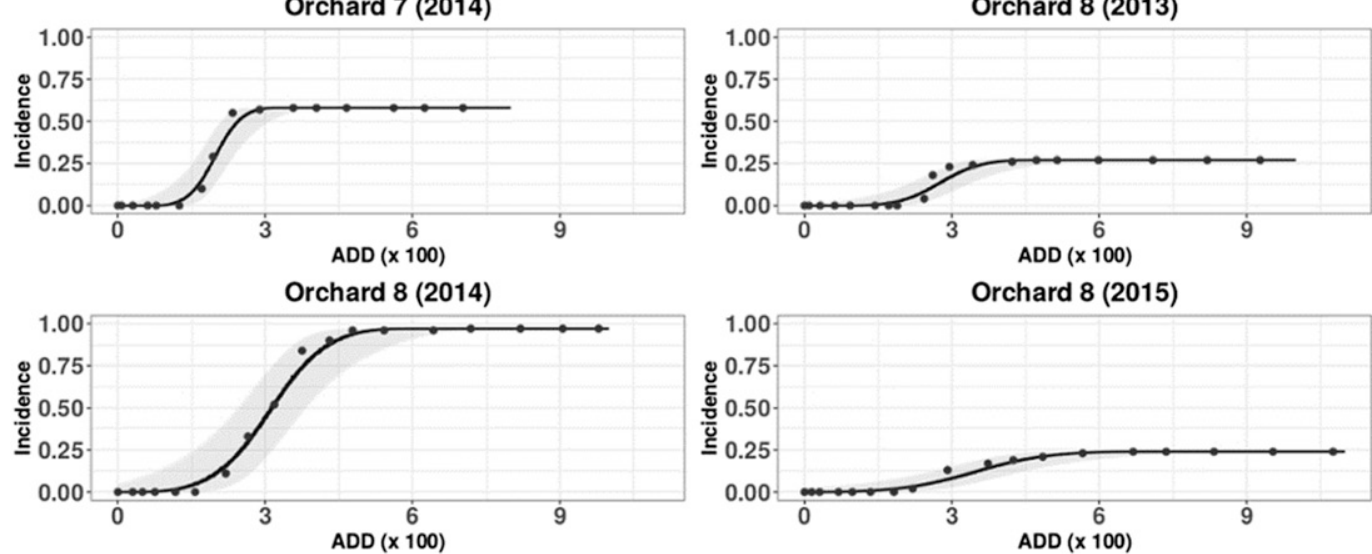

Fig. 1. Dynamics of peach powdery mildew incidence on fruit (solid dots) and accumulated degree-days in the orchards evaluated from 2013 to 2015 . Median posterior distribution (solid line) and $95 \%$ credibility interval (shaded area) obtained with the beta regression models. 


\section{Discussion}

The incidence of PPM in fruit was assessed in different commercial peach and nectarine orchards located in Catalonia, Northeast Spain, across several years. The beta-regression model selected for describing PPM epidemics included two random effects, namely orchard and evaluation year, which were highly relevant in the model, therefore indicating that unmeasured sources of variability were

Table 4. Beta regression models for peach powdery mildew incidence based on environmental variables and their associated WAIC $^{\text {a }}$ values

\begin{tabular}{lc}
\hline Model & WAIC \\
\hline With random effects $^{\mathrm{b}}$ & \\
$\quad$ Intercept + ADD + ADDvpd + ADDwet + & -131.34 \\
$\quad$ WetnessP + v + w & -129.97 \\
$\quad$ Intercept + ADD + ADDvpd + ADDwet + \\
$\quad$ WetnessP + Tm + v + w & -129.32 \\
Intercept + ADD + ADDvpd + ADDwet + & \\
$\quad$ WetnessP + RH + v + w & -129.19 \\
Intercept + ADD + ADDvpd + ADDwet + & \\
$\quad$ WetnessP + Rain + v + w & -128.67 \\
$\quad$ Intercept + ADD + ADDvpd + ADDwet + & \\
$\quad$ Tm + Rain + v + w & -69.98 \\
Without random effects & -69.91 \\
$\quad$ Intercept + ADD & -69.18 \\
Intercept + ADD + Tm & -68.59 \\
$\quad$ Intercept + ADD + ADDvpd + Tm & -68.42 \\
Intercept + ADD + RH & \\
Intercept + ADD + ADDvpd & \\
\hline a Watanabe-Akaike information criterion (Watanabe 2010). \\
b Random effects year (v) and orchard (w).
\end{tabular}

actually driving PPM disease progress after symptom appearance. This was further supported by the poor performance of the model when evaluated with the test dataset. These random sources of variability are likely to be associated with different factors, including cultivar susceptibility, different inoculum levels, and infection dynamics in the orchards among years. These variables were not measured in our study and further experiments would be needed to decipher the random effects and hence optimize the model, e.g., by including additional varieties and orchards under different environmental conditions, and the specific use of spore samplers and trap plants to monitor inoculum and infection dynamics.

Regarding the fixed effects of the beta-regression model developed here, durable wetness and ADD recorded during low VPD conditions (i.e., humid days) had a negative effect on the disease incidence progression. A negative effect of water on the disease progress has been reported for powdery mildews (Jarvis et al. 2002; Yarwood 1957), which is specifically related to the inhibition of conidia germination in free water (Perera and Wheeler 1975; Sivapalan 1993; Yarwood 1957), and the washing off of airborne spores during rain episodes (Blanco et al. 2004). Sutton and Jones (1979) reported that amounts of airborne ascospores of $P$. leucotricha are increased at the beginning of rain episodes but decreased rapidly with continuous rain. Similarly, Grove et al. (2000) reported that rain favors ascospore release of $P$. clandestina. However, conflicting reports on the effects of rain on powdery mildews are notable. Yarwood (1957) described the favorable effect of rain episodes on the incidence progression due to a possible removal of protective applications of fungicides. Other authors pointed out that rainfall induces growth of new susceptible plant tissues (Grove 1995; Ogawa and English 1991). Glawe (2008) and Grove and Boal (1991a, b) argued that dispersion of powdery mildew ascospores may occur after rain or during wetness periods initiated by rain. In our study, when considering ADD under

Table 5. Parameters of the best beta regression model for peach powdery mildew incidence including the fixed effects accumulated degree-days (ADD), ADD considering vapor pressure deficit (ADDvpd), ADD considering vapor pressure deficit and rain (ADDwet), percentage of wetness duration (WetnessP), and the random effects year and orchard. Mean, standard deviation (sd), quantiles $(\mathrm{Q})$, and mode for the parameters and hyperparameters $(\phi, \tau, \rho)$.

\begin{tabular}{|c|c|c|c|c|c|c|}
\hline${ }^{\text {Parameters and hyperparameters }}{ }^{\mathbf{a}}$ & Mean & sd & $Q_{0.025}$ & $Q_{0.5}$ & $Q_{0.975}$ & Mode \\
\hline Intercept & -2.927 & 0.959 & -4.841 & -2.928 & -1.013 & -2.931 \\
\hline $\mathrm{ADD}$ & 0.668 & 0.117 & 0.442 & 0.667 & 0.902 & 0.664 \\
\hline ADDvpd & -2.294 & 0.439 & -3.187 & -2.284 & -1.459 & -2.265 \\
\hline ADDwet & 4.881 & 0.964 & 3.035 & 4.865 & 6.824 & 4.835 \\
\hline WetnessP & -1.891 & 0.599 & -3.063 & -1.892 & -0.711 & -1.896 \\
\hline$\phi$ & 8.999 & 1.763 & 5.969 & 8.856 & 12.867 & 8.591 \\
\hline$\tau$ & 1.091 & 0.922 & 0.156 & 0.841 & 3.518 & 0.429 \\
\hline$\rho$ & 2.008 & 1.361 & 0.449 & 1.676 & 5.532 & 1.113 \\
\hline
\end{tabular}

${ }^{\mathrm{a}} \phi$ is the precision parameter for the beta observations, $\tau$ the precision of the random effect year, and $\rho$ the precision of the random effect orchard.

Table 6. Posterior distributions for the parameters $\left(\beta_{0}, \beta_{1}\right)$ of the beta regression model on the peach powdery mildew disease progression modeling for different orchards and years, including mean, $95 \%$ credibility interval, and standard deviation

\begin{tabular}{|c|c|c|c|c|c|c|c|c|c|}
\hline \multirow[b]{2}{*}{ Year } & \multirow[b]{2}{*}{ Orchard } & \multicolumn{4}{|c|}{$\boldsymbol{\beta}_{0}$ (intercept) } & \multicolumn{3}{|c|}{$\beta_{1}(A D D)^{\mathbf{a}}$} & \multirow[b]{2}{*}{ Std. deviation } \\
\hline & & Mean & 0.025 quant & 0.975 quant & Std. deviation & Mean & 0.025 quant & 0.975 quant & \\
\hline \multirow[t]{6}{*}{2013} & 1 & -12.0 & -16.9 & -7.7 & 2.3 & 3.6 & 2.3 & 5.0 & 0.7 \\
\hline & 2 & -4.9 & -6.2 & -3.6 & 0.7 & 1.6 & 1.2 & 2.0 & 0.2 \\
\hline & 3 & -12.2 & -18.0 & -7.6 & 2.7 & 6.1 & 3.7 & 9.0 & 1.3 \\
\hline & 5 & -9.2 & -12.5 & -6.3 & 1.6 & 2.6 & 1.8 & 3.6 & 0.5 \\
\hline & 7 & -8.3 & -11.5 & -5.4 & 1.5 & 3.6 & 2.4 & 5.1 & 0.7 \\
\hline & 8 & -6.4 & -9.3 & -3.9 & 1.4 & 2.3 & 1.4 & 3.4 & 0.5 \\
\hline \multirow[t]{5}{*}{2014} & 1 & -16.8 & -24.2 & -10.7 & 3.5 & 5.9 & 3.7 & 8.5 & 1.2 \\
\hline & 2 & -6.4 & -8.0 & -4.8 & 0.8 & 2.4 & 1.8 & 3.0 & 0.3 \\
\hline & 6 & -7.1 & -10.0 & -4.5 & 1.4 & 3.6 & 2.3 & 5.1 & 0.7 \\
\hline & 7 & -5.2 & -7.0 & -3.6 & 0.9 & 1.7 & 1.2 & 2.2 & 0.3 \\
\hline & 8 & -13.7 & -19.2 & -9.0 & 2.6 & 4.3 & 2.9 & 5.9 & 0.8 \\
\hline \multirow[t]{3}{*}{2015} & 1 & -7.7 & -10.7 & -5.2 & 1.4 & 2.4 & 1.7 & 3.3 & 0.4 \\
\hline & 6 & -4.6 & -6.2 & -3.1 & 0.8 & 1.3 & 0.9 & 1.8 & 0.2 \\
\hline & 8 & -11.7 & -17.2 & -7.2 & 2.6 & 3.8 & 2.3 & 5.5 & 0.8 \\
\hline
\end{tabular}

${ }^{a}$ Accumulated degree days. 
$>2 \mathrm{~mm}$ rain episodes, a significant positive effect in PPM incidence was obtained. Thus, wetness could be affecting differentially both primary and secondary infections within the pathogen cycle, i.e., by favoring ascospore release but inhibiting conidia germination and washing airborne propagules off from affected plant tissues and environment. In our study, monitoring of PPM incidence and its relationship with ADDwet was performed for the whole infection cycle, so it was not possible for us to evaluate the influence of this variable on each particular stage of PPM epidemics. When analyzing each orchard-year combination separately, ADD was able to successfully describe PPM progression. Air temperature has been previously reported to be one of the main factors affecting the disease progress in powdery mildews (Trecate et al. 2019; Xu and Butt 1998; Yarwood 1957).

Previous works on modeling $P$. pannosa progression on fruit are scarce in literature. Optimal temperature and relative humidity parameters for different phases of the disease cycle have been reported (Grove 1995; Toma and Ivascu 1998). However, Pieters et al. (1993) concluded that neither the temperature nor the relative humidity influenced the differentiation between the two epidemic phases (primary and secondary infections) that were described for $P$. pannosa progression on rose in greenhouse conditions. In contrast, we have shown that combined water and temperature parameters are needed to better explain PPM progression under field conditions.

An epidemiological model for the cherry powdery mildew has been developed (Grove 1991, 1998; Grove and Boal 1991a; Grove et al. 2000). These authors studied the effects of several environmental factors on the development of $P$. clandestina on cherry, such as the release and germination of ascospores depending on temperature and wetness duration (Grove 1991), the germination of conidia on leaves and fruit depending on the temperature and VPD (Grove and Boal 1991a), and the availability of the secondary inoculum based on temperature, relative humidity, and wind speed (Grove 1998). As in the case of cherry powdery mildew, we think that more precise PPM epidemic drivers based on water and temperature can be obtained from future research.

When disease progress was analyzed separately in each orchardyear combination, a robust estimate for the onset of disease was obtained by including only ADD as covariate. We were further able to establish a fungicide program based on a degree-day monitoring with an operating threshold of 220-ADD to initiate fungicide applications, providing growers a reasonable period to mobilize application logistics before the onset of the risk period for PPM. Similarly, Carisse et al. (2009) developed and validated a degree-day

Table 7. Accumulated degree-days calculated by the beta regression model for the studied orchard and year combinations when the incidence of peach powdery mildew in fruit was $0.01,0.02,0.05$, and 0.1

\begin{tabular}{lccccc}
\hline & & \multicolumn{4}{c}{ Disease incidence } \\
\cline { 2 - 6 } Year & Orchard & $\mathbf{0 . 0 1}$ & $\mathbf{0 . 0 2}$ & $\mathbf{0 . 0 5}$ & $\mathbf{0 . 1}$ \\
\hline 2013 & 1 & 278.1 & 296.3 & 327.9 & 389.9 \\
& 2 & 107.2 & 138.0 & 181.0 & 230.0 \\
& 3 & 180.6 & 195.9 & n.a. ${ }^{\mathrm{a}}$ & n.a. \\
& 5 & 246.1 & 264.1 & 293.4 & 327.5 \\
& 7 & 141.0 & 149.2 & 164.3 & 180.4 \\
Mean 2013 & 8 & 166.4 & 187.0 & 221.6 & 261.6 \\
2014 & 1 & 186.6 & 205.1 & 237.6 & 277.9 \\
& 2 & 255.7 & 267.6 & 291.2 & n.a. \\
& 7 & 131.2 & 146.7 & 177.6 & 208.4 \\
& 6 & 260.0 & 271.2 & 291.6 & 315.0 \\
Mean 2014 & 8 & 114.3 & 131.0 & 163.2 & 200.4 \\
2015 & 1 & 174.8 & 188.0 & 213.0 & 221.4 \\
& 6 & 205.8 & 225.4 & 260.8 & 296.6 \\
& 8 & 270.4 & 290.8 & 336.0 & n.a. \\
Mean 2015 & & 150.4 & 188.4 & 257.7 & 333.0 \\
Total means & & 187.1 & 205.4 & 239.1 & 264.0 \\
\hline a n.a. not applicab. & & & & &
\end{tabular}

a n.a.: not applicable. model to initiate a fungicide spray program for the management of grapevine powdery mildew. They concluded that fungicide sprays could be initiated when 1 to $5 \%$ of the total seasonal airborne inoculum was reached, which was depending on the grape variety about 500 to $600 \mathrm{ADD}$ after vines reached the 2 to 3 leaf phenological stage. According to this degree-day model, fungicide applications were initiated 30 to 40 days later (just at the 3 to 4 leaf phenological stage) than those in the standard program. This resulted in a 40 to $55 \%$ reduction in fungicide applications.

For the defined 220-ADD operating threshold, the beta regression model estimated a PPM incidence between 0.02 and 0.05 (with ADD ranging between 205.3 and 239.1 ADD). Thus, the 220-ADD alert spray program is based on synchronizing the initiation of fungicide applications with the detection of the first PPM symptoms. The 220 -ADD alert spray program resulted in an increase of $2.4 \%$ final PPM incidence as compared with the calendar-based program. Although statistically significant because of the relatively large sample size, the size effect of this difference was not relevant in our opinion and, thus, we consider the 220-ADD alert spray program as effective as the current calendar-based spray program. Fungicide sprays in the 220-ADD alert spray program were initiated 24 to 39 days later than in the calendar-based spray program, resulting in an overall reduction of $33 \%$ in the number of fungicide applications. Estimated local cost per each fungicide application (including fungicide, machinery, and personnel costs) in the commercial orchards of our study ranged from $\$ 70$ to $\$ 90$ per ha and application (N. Marimon, unpublished data). Thus, the 220-ADD alert spray program could be a useful tool to optimize PPM control by reducing both production and environmental costs. Further validations would be needed to transfer the 220-ADD alert spray program for PPM management to other cultivars and growing areas with different environmental conditions, including different inoculum potential levels.

We aimed at describing the PPM progress by using a simple model with few variables. We focused on air temperature as this variable is widely available and can be easily recorded at orchard level. Also, DSSs based on this environmental variable are more accessible and easier to implement by growers (Jarvis et al. 2002). Despite the potential advantages foreseen by the implementation of the 220-ADD alert spray program, we assume that epidemiological models including only one or few components of the disease cycle may limit, to

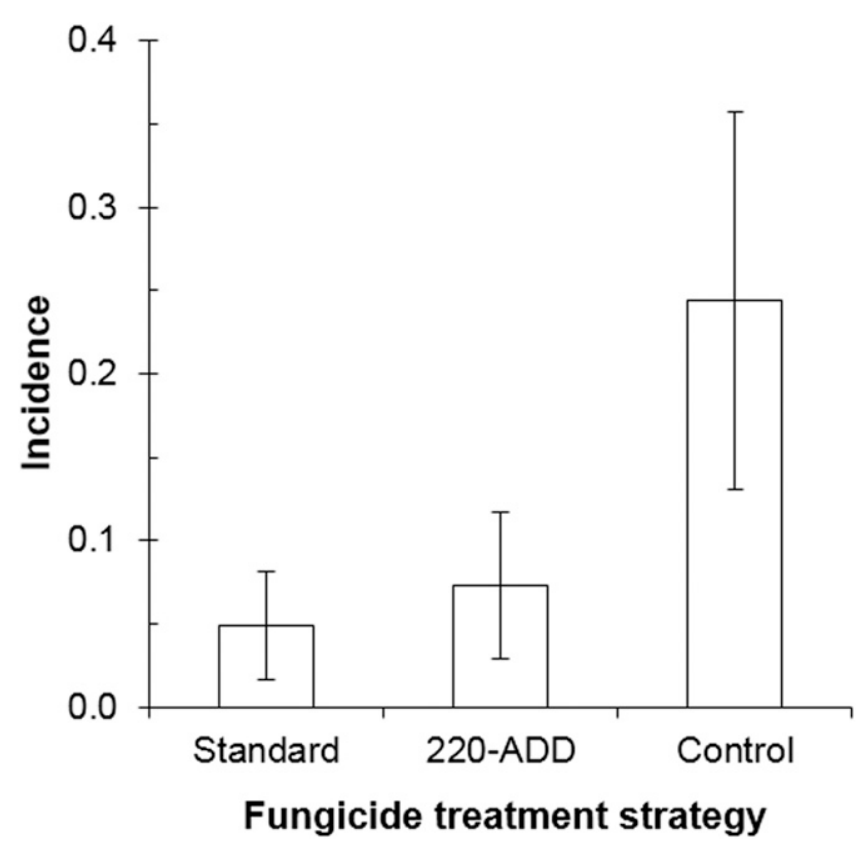

Fig. 2. Peach powdery mildew incidence obtained with a calendar-based fungicide program, fungicide applications initiated after 220 accumulated degree days (ADD), and a nontreated control evaluated in 2017 in a commercial validation. Error bars stand for standard deviation of the mean. 
some extent, model transferability and robustness. Therefore, further work is needed to develop PPM models including additional environmental predictors for the primary and secondary infections on peach fruit. In this sense, the 220-ADD operating threshold described here may be considered as the first component of a future, more complete, DSS for powdery mildew control on peach.

Diversification of fungicides and use of resistant cultivars are the main management strategies used for powdery mildew management worldwide (Cao et al. 2015; Wolfe 1984). Epidemiological models and derived DSSs are also important in integrated disease management. Combining the use of tolerant cultivars with effective DSSs would certainly reduce the amount of fungicides applied while maintaining optimal disease control levels.

\section{Literature Cited}

Amano, K. 1986. Host range and geographical distribution of the powdery mildew fungi. Japan Scientific Societies Press, Tokyo, Japan.

Blanco, C., de Los Santos, B., Barrau, C., Arroyo, F. T., Porras, M., and Romero, F. 2004. Relationship among concentrations of Sphaerotheca macularis conidia in the air, environmental conditions, and the incidence of powdery mildew in strawberry. Plant Dis. 88:878-881.

Butt, D. J. 1978. Epidemiology of powdery mildews. Pages 51-81 in: The powdery mildews. D. M. Spencer, ed. Academic Press, New York.

Cao, X., Yao, D., Xu, X., Zhou, Y., Ding, K., Duan, X., Fan, J., and Luo, Y. 2015. Development of weather- and airborne inoculum-based models to describe disease severity of wheat powdery mildew. Plant Dis. 99:395-400.

Carisse, O., Bacon, R., Lefebvre, A., and Lessard, K. 2009. A degree-day model to initiate fungicide spray programs for management of grape powdery mildew (Erysiphe necator). Plant Pathol. 31:186-194.

De Wolf, E. D., and Isard, S. A. 2007. Disease cycle approach to plant disease prediction. Annu. Rev. Phytopathol. 45:203-220.

Dormann, C. F., Elith, J., Bacher, S., Buchmann, C., Carl, G., Carre, G., GarcíaMárquez, J. R., Gruber, B., Lafourcade, B., Leitao, P. J., Muenkemueller, T., McClean, C., Osborne, P. E., Reineking, B., Schroeder, B., Skidmore, A. K., Zurell, D., and Lautenbach, S. 2013. Collinearity: a review of methods to deal with it and a simulation study evaluating their performance. Ecography 36:27-46.

FAO. 2019. Corporate statistical database - FAOSTAT. Food and Agriculture Organization of the United Nations. Retrieved January 30, 2019, from http:// www.fao.org/faostat/en/\#data/QC

Farr, D. F., and Rossman, A. Y. 2019. Fungal Databases, U.S. National Fungus Collections, ARS, USDA. Retrieved January 30, 2019, from https://nt. ars-grin.gov/fungaldatabases/

Ferrari, S., and Cribari-Neto, F. 2004. Beta regression for modelling rates and proportions. J. Appl. Stat. 31:799-815.

Glawe, D. A. 2008. The powdery mildews: a review of the world's most familiar (yet poorly known) plant pathogens. Annu. Rev. Phytopathol. 46:27-51.

Grove, G. G. 1991. Powdery mildew of sweet cherry: Influence of temperature and wetness duration on release and germination of ascospores of Podosphaera clandestina. Phytopathology 81:1271-1275.

Grove, G. G. 1995. Powdery mildew. Pages 12-14 in: Compendium of Stone Fruit Diseases. J. M. Ogawa, E. I. Zehr, G. W. Bird, D. F. Ritchie, K. Uriu, and J. K. Uyemoto, eds. APS Press, Saint Paul, MN.

Grove, G. G. 1998. Meteorological factors affecting airborne conidia concentrations and the latent period of Podosphaera clandestina on sweet cherry. Plant Dis. 82:741-746.

Grove, G. G., and Boal, R. J. 1991a. Factors affecting germination of conidia of Podosphaera clandestina on leaves and fruit of sweet cherry. Phytopathology $81: 1513-1518$

Grove, G. G., and Boal, R. J. 1991b. Overwinter survival of Podosphaera clandestina in eastern Washington. Phytopathology 81:385-391.

Grove, G. G., Boal, R. J., and Bennett, L. H. 2000. Managing powdery mildew of cherry in Washington orchards and nurseries with spray oils. Plant Health Prog. doi.org/10.1094/PHP-2000-0728-01-RS

Hollomon, D. W., and Wheeler, I. E. 2002. Controlling powdery mildews with chemistry. Pages 249-255 in: The powdery mildews: a comprehensive treatise. R. R. Bélanger, W. R. Bushnell, A. J. Dik, and T. L. W. Carver, eds. APS Press, Saint Paul, MN.

Jarvis, W. R., Gubler, W. D., and Grove, G. G. 2002. Epidemiology of powdery mildews in agricultural pathosystems. Pages 169-198 in: The powdery mildews: a comprehensive treatise. R. R. Bélanger, W. R. Bushnell, A. J. Dik, and T. L. W. Carver, eds. APS Press, Saint Paul, MN.

Jørgensen, L. N., van den Bosch, F., Oliver, R. P., Heick, T. M., and Paveley, N. 2017. Targeting fungicide inputs according to need. Annu. Rev. Phytopathol. 55:181-203.
Kottek, M., Grieser, J., Beck, C., Rudolf, B., and Rubel, F. 2006. World map of the Köppen-Geiger climate classification updated. Meteorol. Z. (Berl.) 15: 259-263.

Madden, L. V., and Ellis, M. A. 1988. How to develop plant disease forecasters Pages 191-208 in: Experimental Techniques in Plant Disease Epidemiology. J. Kranz and J. Rotem, eds. Springer-Verlag, New York.

Magarey, R. D., and Sutton, T. B. 2007. How to create and deploy infection models for plant pathogens. Pages 3-25 in: General Concepts in Integrated Pest and Disease Management. A. Ciancio and K. G. Mukerji, eds. Springer Netherlands, Dordrecht, The Netherlands.

MAPA. 2019. Agriculture Statistics. Official data from the Spanish Ministry of Agriculture, Fisheries, Food and Environment [in Spanish]. Retrieved July 30, 2019, from https:/www.mapa.gob.es/es/estadistica/temas/publicaciones/ anuario-de-estadistica/default.aspx

Martínez-Minaya, J., Conesa, D., López-Quílez, A., Mira, J. L., and Vicent, A. 2019. Modelling inoculum availability of Plurivorosphaerella nawae in persimmon leaf litter with Bayesian beta regression. bioRxiv 771667.

Meier, U., ed. 2001. Growth stages of mono- and dicotyledonous species. BBCH Monograph, 2nd Ed. Biologische Bundesanstalt für Land- und Forstwirtschaft, Braunschweig, Germany.

Nasir, M., Mughal, S. M., Mukhtar, T., and Awan, M. Z. 2014. Powdery mildew of mango: A review of ecology, biology, epidemiology and management. Crop Prot. 64:19-26.

Ogawa, J. M., and Charles, F. M. 1956. Powdery mildew on peach trees. Calif. Agric. 10:7-16.

Ogawa, J. M., and English, H. 1991. Diseases of temperate zone tree fruit and nut crops. University of California, Division of Agriculture and Natural Resources, Oakland, CA.

Perera, R. G., and Wheeler, B. E. J. 1975. Effect of water droplets on the development of Sphaerotheca pannosa on rose leaves. Br. Mycol. Soc. 64: 313-319.

Pieters, M., Wubben, J., Kerssies, A., and Frinking, H. 1993. Development of powdery mildew (Sphaeroteca pannosa) on glasshouse grown roses. Rep. 194. Proefstation voor Bloemisterij en Glas-groente. Aalsmeer, The Netherlands.

R Core Team. 2018. R: A Language and Environment for Statistical Computing. R Foundation for Statistical Computing, Vienna, Austria.

Reuveni, M. 2001. Improved control of powdery mildew (Sphaerotheca pannosa) of nectarines in Israel using strobilurin and polyoxin B fungicides; mixtures with sulfur; and early bloom applications. Crop Prot. 20:663-668.

Rue, H., Martino, S., and Chopin, N. 2009. Approximate Bayesian inference for latent Gaussian models by using integrated nested Laplace approximations.J. Royal Stat. Soc. Ser. B: Stat. Methodol. 71:319-392.

Sapak, Z., Salam, M. U., Minchinton, E. J., MacManus, G. P., Joyce, D., and Galea, V. J. 2017. POMICS: A simulation disease model for timing fungicide applications in management of powdery mildew of cucurbits. Phytopathology 107:1022-1031.

Sivapalan, A. 1993. Effects of water on germination of powdery mildew conidia. Mycol. Res. 97:71-76.

Sutton, T. B., and Jones, A. L. 1979. Analysis of factors affecting dispersal of Podosphaera leucotricha conidia. Phytopathology 69:380-383.

Tierney, L., and Kadane, J. B. 1986. Accurate approximations for posterior moments and marginal densities. J. Am. Stat. Assoc. 81:82-86.

Toma, S., and Ivascu, A. 1998. Highlights of epidemiology of the fungus Sphaerotheca pannosa (Wallr.) Lev. Var. persicae Woron in the southern zone of Romania. Acta Hortic. 465:709-714.

Trecate, L., Sedláková, B., Mieslerová, B., Manstretta, V., Rossi, V., and Lebeda A. 2019. Effect of temperature on infection and development of powdery mildew on cucumber. Plant Pathol. 68:1165-1178.

Watanabe, S. 2010. Asymptotic equivalence of Bayes cross validation and widely applicable information criterion in singular learning theory. J. Mach. Learn. Res. 11:3571-3594.

Weinhold, A. R. 1961. The orchard development of peach powdery mildew. Phytopathology 51:478-481.

Wolfe, M. S. 1984. Trying to understand and control powdery mildew. Plant Pathol. 33:451-466.

$\mathrm{Xu}$, X., and Butt, D. J. 1998. Effects of temperature and atmospheric moisture on the early growth of apple powdery mildew (Podosphaera leucotricha) colonies. Eur. J. Plant Pathol. 104:133-140.

Yarwood, C. E. 1957. Powdery mildews. Bot. Rev. 23:235-301.

Zalom, F. G., Goodell, P. B., Wilson, L. T., Barnett, W. W., and Bentley, W. J. 1983. Degree-days: the calculation and use of heat units in pest management. University of California, Division of Agriculture and Natural Resources, Berkeley, CA. 